\title{
BMJ Open Real-world validation of the minimal disease activity index in psoriatic arthritis: an analysis from a prospective, observational, biological treatment registry
}

Proton Rahman, ${ }_{1}^{1}$ Michel Zummer, ${ }^{2}$ Louis Bessette, ${ }^{3}$ Philip Baer, ${ }^{4}$ Boulos Haraoui, ${ }^{5}$ Andrew Chow, ${ }^{6}$ John Kelsall, ${ }^{7}$ Suneil Kapur, ${ }^{8}$ Emmanouil Rampakakis, ${ }^{9}$ Eliofotisti Psaradellis, ${ }^{9}$ Allen J Lehman, ${ }^{10}$ Francois Nantel, ${ }^{10}$ Brendan Osborne, ${ }^{10}$ Cathy Tkaczyk ${ }^{10}$

To cite: Rahman P, Zummer M, Bessette L, et al. Realworld validation of the minimal disease activity index in psoriatic arthritis: an analysis from a prospective, observational, biological treatment registry. BMJ Open 2017;7:e016619. doi:10.1136/ bmjopen-2017-016619

- Prepublication history and additional material for this paper are available online. To view please visit the journal (http:// dx.doi.org/10.1136/bmjopen2017-016619).

Received 24 February 2017 Revised 8 June 2017 Accepted 19 July 2017

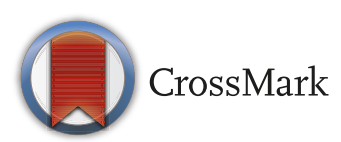

For numbered affiliations see end of article.

Correspondence to Dr Proton Rahman; prahman@mun.ca

\section{ABSTRACT}

Objective To describe the minimal disease activity (MDA) rate over time in patients with psoriatic arthritis (PSA) receiving antitumour necrosis factor agents, evaluate prognostic factors of MDA achievement and identify the most common unmet criteria among MDA achievers.

Design Biologic Treatment Registry Across Canada (BioTRAC): ongoing, prospective registry of patients initiating treatment for rheumatoid arthritis, ankylosing spondylitis or PsA with infliximab (IFX), golimumab (GLM) or ustekinumab.

Setting 46 primary-care Canadian rheumatology practices.

Participants 223 patients with PSA receiving IFX (enrolled since 2005) and GLM (enrolled since 2010) with available MDA information at baseline, 6 months and/or 12 months. Primary and secondary outcome measures MDA was defined as $\geq 5$ of the following criteria: 28 -item tender joint count (TJC28) $\leq 1$, 28-item swollen joint count (SJC28) $\leq 1$, Psoriasis Area and Severity Index (PASI) $\leq 1$ or body surface area $\leq 3$, Pain Visual Analogue Scale (VAS) $\leq 15 \mathrm{~mm}$, patient's global assessment (PtGA) (VAS) $\leq 20 \mathrm{~mm}$, Health Assessment Questionnaire $(\mathrm{HAQ}) \leq 0.5$, tender entheseal points $\leq 1$. Independent prognostic factors of MDA achievement were assessed with multivariate logistic regression.

Results MDA was achieved by $11.7 \%$ of patients at baseline, $43.5 \%$ at 6 months, $44.8 \%$ at 12 months and $48.8 \%$ at either 6 or 12 months. Among MDA achievers at 6 months, $75.7 \%$ had sustained MDA at 12 months. Lower baseline HAQ (OR=0.210; $95 \% \mathrm{Cl}: 0.099$ to 0.447$)$ and lower TJC28 (OR=0.880; 95\% Cl: 0.804 to 0.964 ), were significant prognostic factors of MDA achievement over 12 months of treatment. The most commonly unmet MDA criteria among MDA achievers was patient reported pain (25\%), PtGA (15\%) and PASI (12\%).

Conclusions Almost $50 \%$ of patients treated with IFX or GLM in routine clinical care achieved MDA within the first year of treatment. Lower baseline $\mathrm{HAQ}$ and lower TJC28, were identified as significant prognostic factors of

\section{Strengths and limitations of this study}

- The limitations in the current study are that the peripheral joint activity was measured using the 28-item tender joint count (TJC)/swollen joint count (SJC) although the Outcome Measures in Rheumatology Clinical Trials recommends the measure of 68-item TJC/66-item SJC.

- Furthermore, although several approaches were used to assess disease activity, radiographic images are not collected in Biologic Treatment Registry Across Canada, therefore not allowing the examination of radiographic progression.

- There is also potential bias given the observational nature of the study, a bias that is avoided when using data from clinical trials.

- The strength of the study is that patients were seen in a real-world setting by Canadian rheumatologists during routine clinical practice which enhances the generalisability of the results to the target population.

MDA achievement. The most commonly unmet criteria in patients who achieved MDA were pain, PtGA and PASI. Trial registration number BioTRAC (NCT00741793).

\section{INTRODUCTION}

Psoriatic arthritis (PsA) is a chronic systemic inflammatory musculoskeletal disease characterised by synovitis, axial disease, enthesitis or dactylitis and psoriasis. It is variably associated with other extra-articular manifestations that affects women and men equally. ${ }^{1}$ PsA also affects up to $30 \%$ to $40 \%$ of patients with psoriasis. ${ }^{2}$ Previously PsA was considered a mild disease; however, evidence from the last two decades has shown that it is frequently an erosive and deforming disease in $40 \%$ to $60 \%$ of patients who are diagnosed within 
the first few years. ${ }^{3-5}$ Furthermore, similarly to other rheumatic diseases such as rheumatoid arthritis (RA), PsA has been associated with impaired physical function, reduced quality of life (QOL) and increased mortality, ${ }^{6-8}$ with about $20 \%$ of patients eventually developing a highly destructive and disabling form of PsA. ${ }^{9}$ Manifestations of PsA contribute to disease burden due to the negative effects on the patient's psychological and psychosocial functioning, dissatisfaction with the management of the disease and the negative impact on daily living activities. ${ }^{10}$

Over the years, major clinical improvements have been achieved in the outcome of inflammatory rheumatic diseases due to improved treatment availability and more commonly adopted early treatment algorithms including the treat-to-target strategy which has become the standard of care for newly diagnosed patients in RA. ${ }^{11}{ }^{12}$ Treatment therapies in PsA such as tumour necrosis factor- $\alpha$ blockers (anti-TNF- $\alpha$ ) have demonstrated a reduction in disease activity and radiographic progression of joint damage. ${ }^{13-15}$ Although remission remains the ultimate treatment goal, the complexity of PsA makes it difficult to identify valid criteria that mark a state of remission or low disease activity that take into account all dimensions of the clinical manifestations of the disease. In the past decades, different scores were used to evaluate the disease severity of PsA such as the Disease Activity Score using 28 joints (DAS28) originally developed for RA assessment, as well as the Psoriatic Arthritis Disease Activity Score, a weighted index comprising assessments of joints, function, acutephase response, QOL and patient and physician global Visual Analogue Scale (VAS) scores and the Composite Psoriatic Disease Activity Index which takes into account the assessment of different domains such as peripheral arthritis, skin disease, spinal disease, dactylitis and enthesitis. The minimal disease activity (MDA) was developed to take into account the heterogeneity seen and measure the disease activity of several clinical domains which is a more suitable outcome measure compared with DAS28 which does not take into consideration the full spectrum of disease manifestations. ${ }^{16}$ These MDA criteria were validated in randomised controlled trials and observational studies demonstrating that patients who achieved MDA for a period of 12 months or more experienced a reduction in radiographic joint damage progression. ${ }^{17} 18$ The tight control of inflammation in early psoriatic arthritis trial was the first randomised controlled trial, with a treat-to-target approach in patients with PsA where the tight control group were reviewed every 4 weeks with escalation of treatment if MDA criteria was not met. Patients in the tight control group showed significant improvements in joint and skin disease activity, as well as benefits in function and QOL compared with the standard of care group. ${ }^{19}$ However as far as we know, no real-world evidence data on MDA are available in the literature.

The aim of the current study is to (1) describe the rate of MDA achievement over time, (2) evaluate prognostic factors of MDA achievement, (3) assess which unmet criteria were more common among patients who achieved MDA, (4) evaluate which unmet criteria were more common among patients who were near MDA achievers and (5) assess DAS28 remission, DAS28 deep remission and the level of agreement between MDA and DAS28 remission in patients with PsA treated with infliximab (IFX) or golimumab (GLM), in a routine clinical practice setting. The analysis was done using data from the Biologic Treatment Registry Across Canada (BioTRAC), an ongoing, community-based, Canada-wide, multicentre, prospective, observational registry of patients with inflammatory arthritis.

\section{METHODS \\ Study design}

BioTRAC is an ongoing Canadian multicentre, prospective, observational registry collecting real-world clinical, laboratory, patient-centric and safety data in RA, ankylosing spondylitis and patients with PsA treated with IFX, GLM or ustekinumab as part of their routine care. The historical development of the registry has been described by Thorne et al. ${ }^{20}$ To date there are over 100 rheumatology sites, participating, both in an institutional and private setting, with over 2100 patients enrolled in the programme across all indications. In accordance with the observational nature of the registry, there is no protocol-defined intervention in patient management. All clinical decisions and treatments are based on routine practice and the judgement of the treating physicians. Patients provided written informed consent prior to participation in the study. Ethics approval for participation in the BioTRAC programme was obtained from the respective Research Ethics Boards of participating institutional sites and a Central Institutional Review Board (IRB Services, Ontario Canada) for private practice sites. BioTRAC is conducted according to the tenets of the Declaration of Helsinki.

\section{Study population}

Biologic-naive patients or patients previously treated with one biologic who are eligible for treatment with IFX, GLM or ustekinumab as per their respective Canadian Product Monograph are considered for inclusion in the registry. For the purpose of the current analysis, 223 patients with PsA treated with IFX (enrolled since 2005) or with GLM (enrolled since 2010) were included from 46 primary care rheumatology practices across Canada. All efficacy analyses were observed and included all enrolled patients with PsA who received at least one dose of IFX or GLM and had at least one follow-up assessment with available MDA data at 6 or 12 months. Figure 1 represents the flow chart of the patient population over time.

\section{Data collection}

The following clinical/laboratory parameters and patient reported outcomes are collected as per routine care at baseline and at all follow-up visits, with suggested 


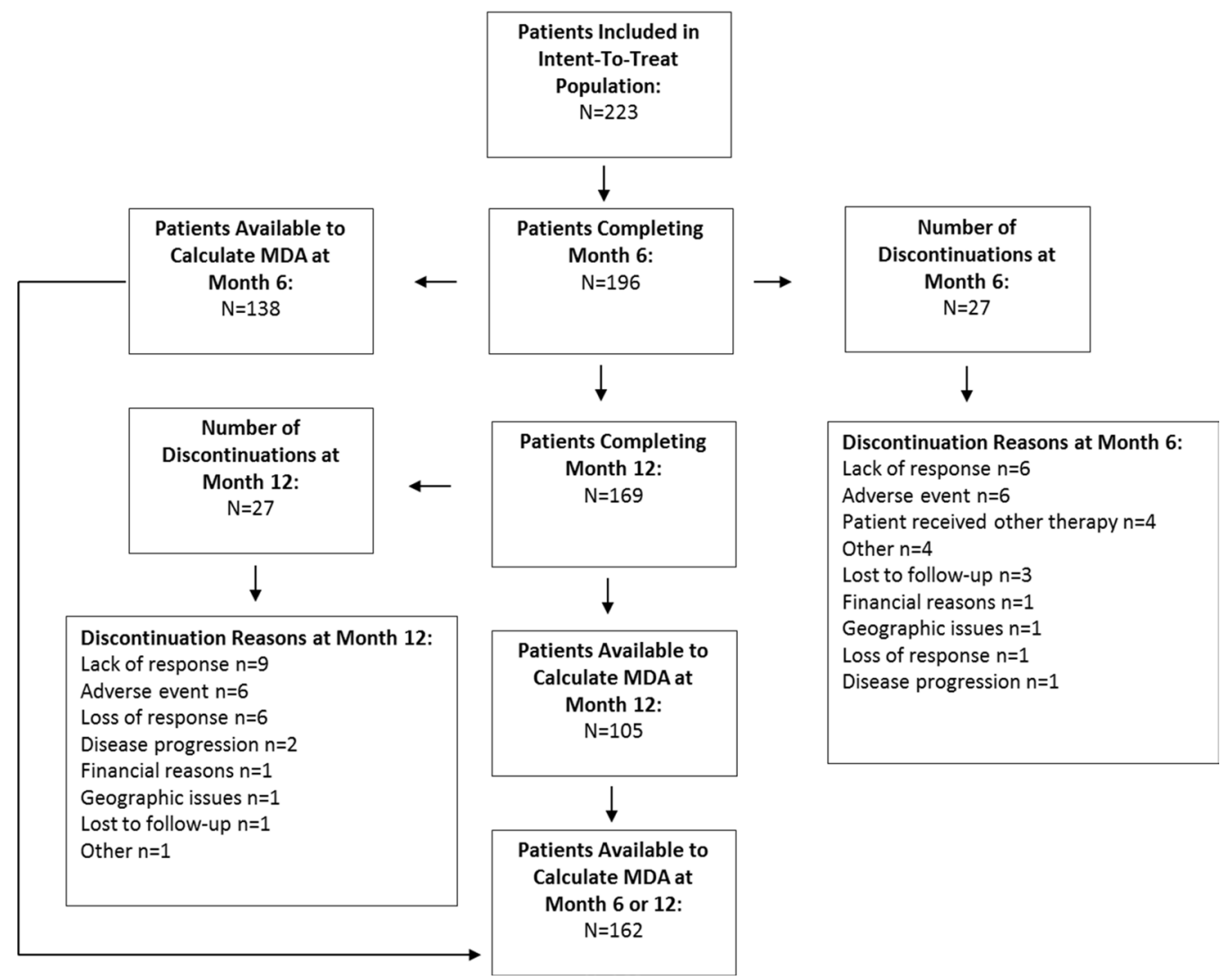

Figure 1 Flow chart of the patient population over time. MDA, minimal disease activity.

assessments every 6 months given that this is within acceptable practice patterns for patients with active PsA: morning (AM) stiffness, swollen joint count (SJC28), tender joint count (TJC28), patient's global assessment (PtGA) and physician's global assessment of disease activity (MDGA), Health Assessment Questionnaire (HAQ), patient's assessment of pain, $\mathrm{C}$ reactive protein (CRP) and erythrocyte sedimentation rate (ESR).

\section{Statistical analysis}

Descriptive statistics included mean and SD for continuous variables and proportions for categorical variables. The absolute improvement in disease parameters at 6 and 12 months of treatment was assessed with the non-parametric Wilcoxon signed-rank test, while between-group differences for continuous and categorical variables were assessed with the non-parametric Kruskal-Wallis test and the Pearson $\chi^{2}$ test, respectively. The improvement in MDA achievement, DAS28 remission $(<2.6)$ and DAS28 deep remission $(<1.98)$ over time was assessed for statistical significance with the McNemar test. Independent prognostic factors of MDA achievement at 6 or 12 months of treatment were assessed with backward conditional logistic regression; covariates considered were: province, gender, age, baseline biological agent, MDGA, PtGA, pain, HAQ, SJC28, TJC28 and enthesitis count with probability for stepwise entry and removal at the 0.05 and 0.10 level, respectively. MDA was defined as the fulfilment of $\geq 5$ of the following criteria: TJC28 $\leq 1$, SJC28 $\leq 1$, Psoriasis Area and Severity Index (PASI) $\leq 1$, pain (VAS) $\leq 15 \mathrm{~mm}$, PtGA (VAS) $\leq 20 \mathrm{~mm}, \mathrm{HAQ} \leq 0.5$, tender entheseal points $\leq 1 .{ }^{18}$ Modified MDA (mMDA) was defined as having skin and swollen joints as mandatory criteria of the $5 / 7$ criteria. Near MDA was defined as fulfilment of $4 / 7$ criteria. Patients with missing information included gender $(n=21)$, age $(n=89)$, disease duration $(\mathrm{n}=76)$, while baseline parameters for DAS28 $(n=49)$, MDGA $(n=31)$, CRP $(n=51)$, ESR $(n=48)$, AM stiffness $(n=34)$ and TJC28, SJC28, PtGA, HAQ, pain, PASI (all, $n=27$ ). Furthermore $12 \%, 30 \%$ and $38 \%$ of patients had missing MDA at baseline, 6-month and 12-month follow-up, respectively (see figure 1). DAPSA was defined as the sum of TJC28, SJC28, CRP (mg/dL), PtGA (VAS 0-10) and pain (VAS 0-10). There was no imputation of missing data in the current analysis. Statistical analyses were conducted with SPSS V.21.0.

\section{RESULTS}

Table 1 summarises the patient demographics and characteristics by region at baseline. There were 130 (58.3\%) and $93(41.7 \%)$ patients on GLM and IFX, respectively. Mean (SD) age and disease duration was 49.8 (11.1) and 5.4 (6.3) years, respectively, and $45.3 \%$ were men. Baseline disease parameters for DAS28, TJC28, SJC28, pain, PtGA, MDGA, morning stiffness, HAQ, CRP and ESR were statistically comparable at baseline among Canadian regions. However significant differences between regional groups were observed at baseline for mean (SD) 
Table 1 Demographics and disease characteristics by region at baseline

\begin{tabular}{|c|c|c|c|c|c|c|}
\hline Parameter & $\begin{array}{l}\text { Western } \\
(n=18)\end{array}$ & $\begin{array}{l}\text { Ontario } \\
(n=111)\end{array}$ & $\begin{array}{l}\text { Quebec } \\
(n=63)\end{array}$ & $\begin{array}{l}\text { Maritimes } \\
(n=31)\end{array}$ & $\mathrm{p}$ Value & $\begin{array}{l}\text { Total } \\
(\mathrm{N}=223)\end{array}$ \\
\hline \multicolumn{7}{|l|}{ Sociodemographics } \\
\hline \multicolumn{7}{|l|}{ Gender, n (\%) } \\
\hline Male & $5(27.8)$ & $44(39.6)$ & $35(55.6)$ & $17(54.8)$ & 0.107 & $101(45.3)$ \\
\hline Female & $8(44.4)$ & $58(52.3)$ & $25(39.77)$ & $10(32.3)$ & & $101(45.3)$ \\
\hline Missing & $5(27.8)$ & $9(8.1)$ & $3(4.8)$ & $4(12.9)$ & & $21(9.4)$ \\
\hline Age (years), mean (SD) & $50.7(14.6)$ & $49.7(10.7)$ & $51.0(11.6)$ & $46.5(9.9)$ & 0.393 & $49.8(11.1)$ \\
\hline \multicolumn{7}{|l|}{ Disease parameters, mean (SD) } \\
\hline Disease duration (years) & $4.0(4.6)$ & $5.4(6.2)$ & $7.5(7.4)$ & $1.9(2.0)$ & 0.002 & $5.4(6.3)$ \\
\hline DAS28 & $4.3(0.8)$ & $4.4(1.7)$ & $4.2(1.3)$ & $4.3(1.8)$ & 0.928 & $4.3(1.6)$ \\
\hline TJC28 & $8.1(6.4)$ & $7.1(6.7)$ & $5.8(5.0)$ & $9.0(9.2)$ & 0.555 & $7.0(6.7)$ \\
\hline SJC28 & $4.1(3.8)$ & $4.6(4.7)$ & $5.2(4.1)$ & $5.0(5.1)$ & 0.549 & $4.8(4.5)$ \\
\hline MDGA (VAS cm) & $6.0(2.1)$ & $5.1(2.4)$ & $5.5(2.3)$ & $4.6(1.4)$ & 0.062 & $5.2(2.2)$ \\
\hline PtGA (VAS mm) & $54.5(27.1)$ & $52.0(28.3)$ & $49.5(22.2)$ & $46.0(25.6)$ & 0.662 & $50.5(26.1)$ \\
\hline AM stiffness* $(\min )$ & $54.6(49.2)$ & $48.1(47.6)$ & $35.5(39.8)$ & $49.1(43.3)$ & 0.237 & $45.0(45.0)$ \\
\hline $\mathrm{HAQ}$ & $1.3(0.5)$ & $1.1(0.7)$ & $1.1(0.6)$ & $1.0(0.7)$ & 0.263 & $1.1(0.7)$ \\
\hline Pain (VAS mm) & $47.9(23.0)$ & $49.2(27.5)$ & $48.4(23.0)$ & $40.7(23.6)$ & 0.492 & $47.6(25.4)$ \\
\hline PASI & $3.8(4.2)$ & $3.7(5.4)$ & $1.4(2.9)$ & $1.2(1.5)$ & $<0.001$ & $2.6(4.4)$ \\
\hline Enthesitis count $†$ & $6.8(3.3)$ & $4.6(4.2)$ & $3.4(2.1)$ & $5.8(3.6)$ & 0.012 & $4.9(3.5)$ \\
\hline ESR (mm/hour) & $14.0(15.3)$ & $22.5(22.9)$ & $19.4(16.4)$ & $19.0(22.3)$ & 0.566 & $20.7(20.7)$ \\
\hline $\mathrm{CRP}(\mathrm{mg} / \mathrm{L})$ & $12.4(13.6)$ & $17.7(36.9)$ & $10.7(14.2)$ & $14.1(27.6)$ & 0.952 & $14.7(29.1)$ \\
\hline \multicolumn{7}{|l|}{ Medications, n (\%) } \\
\hline \multicolumn{7}{|l|}{ Baseline biological agent } \\
\hline GLM & $8(44.4)$ & $69(62.2)$ & 39 (61.9) & $14(45.2)$ & 0.200 & $130(58.3)$ \\
\hline IFX & $10(55.6)$ & $42(37.8)$ & $24(38.1)$ & $17(54.8)$ & & $93(41.7)$ \\
\hline Previous biologic & $3(16.7)$ & $5(4.5)$ & $10(15.9)$ & $7(22.6)$ & 0.012 & $25(11.2)$ \\
\hline Previous DMARD & $12(66.7)$ & $59(53.2)$ & $47(74.6)$ & $21(67.7)$ & 0.036 & $139(62.3)$ \\
\hline Previous corticosteroid & $6(33.3)$ & $17(15.3)$ & $21(33.3)$ & $3(9.7)$ & 0.008 & $47(21.1)$ \\
\hline Concomitant DMARD & $11(61.1)$ & $52(46.8)$ & $40(63.5)$ & $19(61.3)$ & 0.135 & $122(54.7)$ \\
\hline Concomitant methotrexate & $4(22.2)$ & $43(38.7)$ & $35(55.6)$ & $16(51.6)$ & 0.031 & 98 (43.9) \\
\hline Concomitant corticosteroid use & $1(5.6)$ & $10(9.0)$ & $7(11.1)$ & $2(6.5)$ & 0.837 & $20(9.0)$ \\
\hline
\end{tabular}

*Capped at 120 minutes.

†Among patients with enthesitis.

AM, morning; CRP, C reactive protein; DMARD, disease-modifying antirheumatic drug; DAS28, Disease Activity Score using 28 joints; ESR, erythrocyte sedimentation rate;GLM, golimumab; HAQ, Health Assessment Questionnaire; IFX, infliximab; MDGA, physician global assessment of disease activity; PASI, Psoriasis Area and Severity Index; PtGA, patient global assessment of disease activity; SJC, 28-item swollen joint count; TJC, 28-item tender joint count; VAS, Visual Analogue Scale.

disease duration $(\mathrm{p}=0.002)$, enthesitis count (Western: 6.8 (3.3), Ontario: 4.6 (4.2), Quebec: 3.4 (2.1), Maritime: $5.8(3.6) ; \mathrm{p}=0.012)$ and PASI (Western: $3.8(4.2)$, Ontario: 3.7 (5.4), Quebec: 1.4 (2.9), Maritime: 1.2 $(1.5) ; \mathrm{p}<0.001)$. Furthermore, use of a previous biologic $(\mathrm{p}=0.017)$, previous DMARD $(\mathrm{p}=0.047)$, previous corticosteroid $(\mathrm{p}=0.006)$ and concomitant methotrexate use ( $\mathrm{p}=0.031)$ showed significant between group differences among regions (table 1).

All disease parameters showed statistically significant improvement over time from baseline to month 6 and month $12(\mathrm{p}<0.05)$ (online supplementary figure 1$)$.
Figure 2 describes achievement of MDA, mMDA, DAS28 remission, DAS28 deep remission and DAPSA remission over time. At baseline, 6 and 12 months of treatment, $11.7 \%, 43.5 \%$ and $44.8 \%$ of patients achieved MDA, respectively, while $48.8 \%$ achieved MDA at 6 or 12 months. Additionally, 34.6\% ( $\mathrm{n}=28 / 81)$ achieved MDA at both 6 and 12 months of treatment (overall sustained MDA). Patients achieving mMDA at baseline, 6 and 12 months was $7.1 \%, 37.7 \%$ and $36.2 \%$, respectively. DAS28 remission $(<2.6)$ was achieved by $14.4 \%, 50.0 \%$ and $48.8 \%$ of patients, DAS28 deep remission $(<1.98)$ by $8.6 \%$, $33.9 \%$ and $28.6 \%$ and DAPSA remission $(\leq 4)$, by $6.4 \%$, 


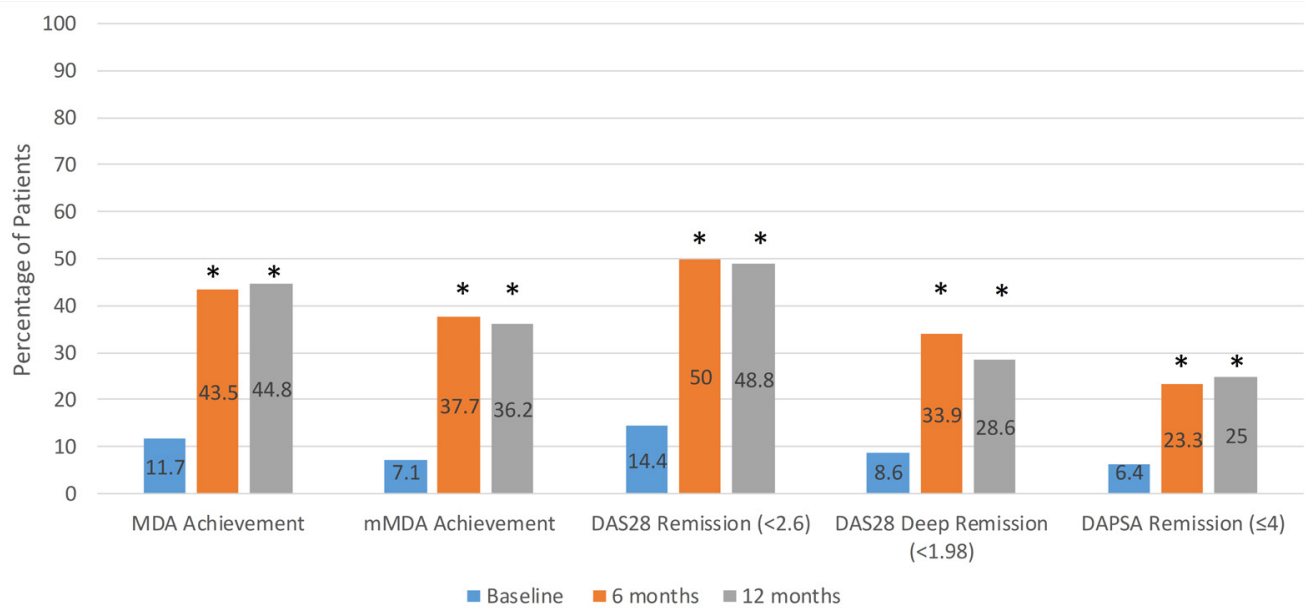

Figure 2 MDA achievement, mMDA achievement, DAS28 remission, DAS28 deep remission and DAPSA remission over time. *The improvement in MDA achievement, mMDA achievement, DAS28 remission, DAS28 deep remission and DAPSA remission from baseline to 6 months and from baseline to 12 months was assessed with the McNemar test $(p<0.001$ for all, except DAS28 deep remission at 12 months $p=0.019$; and DAPSA remission at 12 months $p=0.006$ ). DAPSA, Disease Activity in PSoriatic Arthritis; DAS28, Disease Activity Score using 28 joints; MDA, minimal disease activity; mMDA, modified MDA.

$23.3 \%$ and $25.0 \%$ at baseline, 6 months and 12 months of treatment, respectively (figure 2). The improvement in MDA achievement, DAS28 remission and DAS28 deep remission from baseline to 6 months and 12 months was statistically significant for all measures of disease activity $(\mathrm{p}<0.05)$. Table 2 depicts sensitivity, specificity, positive and negative predictive values between MDA or mMDA

\begin{tabular}{|c|c|c|c|}
\hline $\begin{array}{l}\text { Diagnostic criteria } \\
\text { definitions }\end{array}$ & $\begin{array}{l}\text { DAS28 } \\
\text { remission } \\
(<2.6)\end{array}$ & $\begin{array}{l}\text { DAS28 deep } \\
\text { remission } \\
(<1.98)\end{array}$ & $\begin{array}{l}\text { DAPSA } \\
\text { remission } \\
(\leq 4)\end{array}$ \\
\hline \multicolumn{4}{|l|}{ MDA } \\
\hline Sensitivity & $70.7 \%$ & $82.1 \%$ & $100.0 \%$ \\
\hline Specificity & $92.3 \%$ & $85.7 \%$ & $85.9 \%$ \\
\hline $\begin{array}{l}\text { Positive predictive } \\
\text { value }\end{array}$ & $82.1 \%$ & $60.4 \%$ & $56.3 \%$ \\
\hline $\begin{array}{l}\text { Negative predictive } \\
\text { value }\end{array}$ & $86.4 \%$ & $94.7 \%$ & $100.0 \%$ \\
\hline $\begin{array}{l}\text { Kappa agreement } \\
\text { (K) }\end{array}$ & 0.653 & 0.598 & 0.652 \\
\hline \multicolumn{4}{|l|}{ mMDA } \\
\hline Sensitivity & $57.7 \%$ & $71.8 \%$ & $87.0 \%$ \\
\hline Specificity & $94.8 \%$ & $90.4 \%$ & $89.9 \%$ \\
\hline $\begin{array}{l}\text { Positive predictive } \\
\text { value }\end{array}$ & $84.5 \%$ & $66.7 \%$ & $61.0 \%$ \\
\hline $\begin{array}{l}\text { Negative predictive } \\
\text { value }\end{array}$ & $81.9 \%$ & $92.3 \%$ & $97.5 \%$ \\
\hline $\begin{array}{l}\text { Kappa agreement } \\
\text { (K) }\end{array}$ & 0.570 & 0.605 & 0.655 \\
\hline
\end{tabular}

DAPSA, Disease Activity in PSoriatic Arthritis; DAS28, Disease Activity Score using 28 joints; MDA, minimal disease activity; mMDA, modified MDA. and DAS28 remission, DAS28 deep remission, as well as DAPSA remission. There was substantial agreement between MDA and DAS28 remission as well as MDA and DAPSA remission with a Kappa measure of agreement of 0.653 and 0.652 , respectively (both $\mathrm{p}<0.001$ ) while that between MDA and DAS28 deep remission showed moderate agreement with $0.598(\mathrm{p}<0.001)$. Similar results were observed for the association of mMDA with the relevant outcome measures.

Univariate analysis (table 3 ) showed that male gender $(\mathrm{p}=0.031)$ and lower age $(\mathrm{p}=0.011)$ were significantly associated with MDA achievement at 6 or 12 months of treatment. Furthermore, significant between-region differences were observed for MDA achievement at 6 or 12 months of treatment $(\mathrm{p}=0.019)$. Ontario and Quebec patients had the highest MDA rates with $56.0 \%$ and $52.9 \%$, respectively, while $36.4 \%$ and $14.3 \%$ of patients in Maritime and Western provinces reached MDA, respectively. In addition, significantly lower disease severity was observed at baseline among MDA achievers for the following disease parameters: MDGA $(\mathrm{p}<0.001)$, PtGA $(\mathrm{p}<0.001)$, pain $(\mathrm{p}<0.001)$, HAQ $(\mathrm{p}<0.001)$, SJC28 $(\mathrm{p}=0.001)$, TJC28 $(\mathrm{p}<0.001)$ and enthesitis count $(\mathrm{p}=0.013)$. Multivariate logistic regression analysis (table 4) showed that lower baseline HAQ $(\mathrm{OR}=0.210, \mathrm{p}<0.001)$ and lower TJC28 $(\mathrm{OR}=0.880, \mathrm{p}=0.006)$ were significant prognostic factors of MDA achievement over 12 months of treatment, while parameters of lower enthesitis count $(\mathrm{OR}=0.838, \mathrm{p}=0.069)$ and GLM as the biological agent $(\mathrm{OR}=2.228, \mathrm{p}=0.073)$ showed a trend towards statistical significance. Overall, similar results were obtained when assessing predictors of mMDA instead of MDA (data not shown).

Among the patients who achieved MDA at any time point, the highest proportion met all 7 MDA criteria with $45.8 \%$, while $24.4 \%$ met $6 / 7$ criteria and $29.8 \%$ met $5 / 7$ criteria (figure $3 \mathrm{~A}$ ). The most commonly unmet 
Table 3 Univariate analysis for MDA achievement at 6 or 12 months of treatment

\section{MDA achievement at 6 or 12 months}

\begin{tabular}{|c|c|c|c|}
\hline Parameters & Yes & No & p Value* \\
\hline \multicolumn{4}{|l|}{ Province, n (\%) } \\
\hline Western & $2(14.3)$ & $12(85.7)$ & 0.019 \\
\hline Ontario & $42(56.0)$ & $33(44.0)$ & \\
\hline Quebec & $27(52.9)$ & $24(47.1)$ & \\
\hline Maritimes & $8(36.4)$ & $14(63.6)$ & \\
\hline \multicolumn{4}{|l|}{ Gender, n (\%) } \\
\hline Male & $45(59.2)$ & $31(40.8)$ & 0.031 \\
\hline Female & $28(40.6)$ & $41(59.4)$ & \\
\hline Age, mean (SD) & $46.6(12.0)$ & $51.6(10.7)$ & 0.011 \\
\hline $\begin{array}{l}\text { MDGA (VAS cm) } \dagger \text {, } \\
\text { mean (SD) }\end{array}$ & $4.3(2.4)$ & $5.9(2.0)$ & $<0.001$ \\
\hline $\begin{array}{l}\text { PtGA (VAS mm)†, } \\
\text { mean (SD) }\end{array}$ & $39.7(24.7)$ & $56.8(24.9)$ & $<0.001$ \\
\hline $\begin{array}{l}\text { Pain (VAS mm)†, } \\
\text { mean (SD) }\end{array}$ & $35.6(24.4)$ & $55.1(23.2)$ & $<0.001$ \\
\hline HAQ†, mean (SD) & $0.7(0.6)$ & $1.3(0.6)$ & $<0.001$ \\
\hline SJC28†, mean (SD) & $3.4(3.8)$ & $5.4(4.4)$ & 0.001 \\
\hline TJC28†, mean (SD) & $3.8(4.1)$ & $8.8(6.8)$ & $<0.001$ \\
\hline $\begin{array}{l}\text { Enthesitis count } †, \ddagger \text {, } \\
\text { mean (SD) }\end{array}$ & $0.7(1.4)$ & $2.0(3.3)$ & 0.013 \\
\hline \multicolumn{4}{|l|}{$\begin{array}{l}\text { Baseline biological } \\
\text { agent }\end{array}$} \\
\hline GLM & 48 (53.9) & $41(46.1)$ & 0.158 \\
\hline IFX & $31(42.5)$ & $42(57.5)$ & \\
\hline
\end{tabular}

${ }^{*} \mathrm{p}$ Value was assessed with $\chi^{2}$ for categorical variables or with non-parametric Mann-Whitney $U$ test for continuous variables. †Denotes disease parameters at baseline. $\ddagger$ Among all patients (with and without enthesitis).

GLM, golimumab; HAQ, Health Assessment Questionnaire; IFX, infliximab; MDA, minimal disease activity; MDGA, physician's global assessment of disease activity; PtGA, patient's global assessment; SJC28, 28-item swollen joint count; TJC28, 28-item tender joint count; VAS, Visual Analogue Scale.

criteria among these cases were patient-reported pain (with 25.2\%), PtGA (with 15.3\%) and PASI (with 12.2\%) (figure 3B). Additionally, among the 309 instances of non-MDA achievement, the proportion of cases that achieved near MDA was $16.5 \%$ (51/309). The most common reason for non-MDA in near-MDA cases was patient-reported pain $(82.4 \%)$ followed by PtGA $(68.6 \%)$ and HAQ (60.8\%) (figure 3C). Interestingly, nine patients with available data that had reached MDA at 6 months were not in MDA state after 12 months. It was determined that the most common criteria not met in this group were: PtGA (88.9\%), enthesitis count (66.7\%), TJC (55.6\%) and PASI (33.3\%).
Table 4 Multivariate analysis for minimal disease activity achievement at 6 or 12 months of treatment

95\% Cls for

OR

\begin{tabular}{llllll}
\cline { 4 - 5 } Parameters & Beta & OR & Lower & Upper & p Value \\
\hline Baseline HAQ & -1.561 & 0.210 & 0.099 & 0.447 & $<0.001$ \\
\hline Baseline TJC28 & -0.128 & 0.880 & 0.804 & 0.964 & 0.006 \\
$\begin{array}{l}\text { Baseline } \\
\text { enthesitis count }\end{array}$ & -0.177 & 0.838 & 0.692 & 1.014 & 0.069 \\
$\begin{array}{l}\text { Baseline } \\
\text { biological agent: }\end{array}$ & 0.801 & 2.228 & 0.929 & 5.343 & 0.073 \\
$\begin{array}{l}\text { GLM vs IFX } \\
\text { MLM }\end{array}$ & & & & & \\
\hline
\end{tabular}

Multivariate analysis was assessed with backward conditional logistic regression, covariates entered were: province, gender, age, baseline biologic agent, MDGA, PtGA, Pain, HAQ, SJC28, TJC28 and enthesitis count with probability for stepwise entry and removal

at the 0.05 and 0.10 level, respectively.

GLM, golimumab; HAQ, Health Assessment Questionnaire; IFX, infliximab; TJC28, 28-item tender joint count.

\section{DISCUSSION}

The current analysis is the first community-based Canadian study presenting a 12-month follow-up of 223 prospectively followed patients with PsA from the BioTRAC registry. All measures of disease activity in the current study showed a statistical improvement over time $(\mathrm{p}<0.05)$.

Reported MDA achievement at 6 and 12 months of treatment was comparable with $43.5 \%$ and $44.8 \%$, respectively. Among MDA achievers at 6 months, $75.7 \%(\mathrm{n}=28 / 37)$ had sustained MDA at 12 months. The MDA achievement rate of approximately $45 \%$ is in line with the rates reported by Mease $e t$ al despite the randomised controlled setting of this study. ${ }^{21}$ However, our findings are lower in comparison with two recent studies which reported that $64 \%$ of the study population achieved MDA after 12 months of treatment with anti TNF- $\alpha$ therapy. ${ }^{22}{ }^{23}$ A slightly higher proportion of patients $(48.8 \%)$ achieved DAS28 remission at 12 months compared with MDA, while the rates of mMDA (36.2\%), DAS28 deep remission (28.6\%) and DAPSA remission (25.0\%) were lower suggesting that the latter measures are more strict. However, the MDA had substantial agreement with DAS28 and DAPSA remission, whereas moderate agreement was observed with DAS28 deep remission. Thus, the current analysis suggests that MDA criteria may be a more powerful and discriminatory method to assess PsA than DAS28. The simplicity in calculating MDA and the lack of requirement for acute phase reactants at the time of visit as compared with the DAS28, makes the MDA a more desirable and practical tool to measure disease outcome in PsA.

Adjusted analysis of baseline variables showed that lower HAQ, lower TJC28, lower enthesitis count and GLM as the biological agent were considered independent prognostic factors of MDA achievement over 12 months of treatment. In addition to $\mathrm{HAQ}^{24}{ }^{25}$ previous 

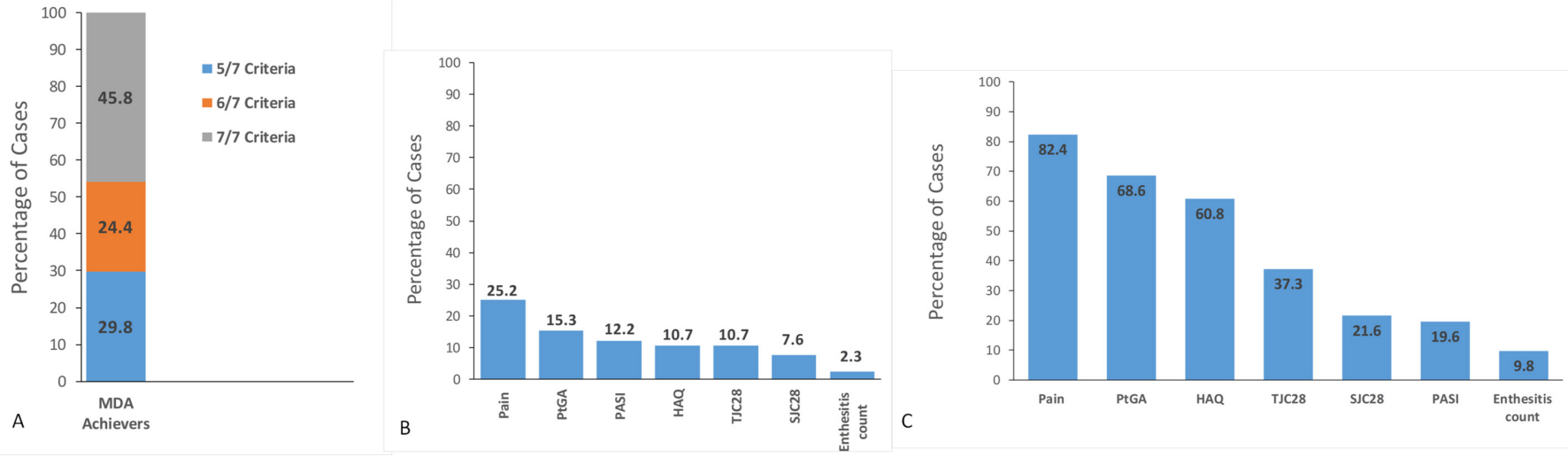

Figure 3 (A) Proportion of met criteria among minimal disease activity (MDA) achievers. (B) Proportion of unmet disease criteria among MDA achievers. (C) Proportion of Unmet criteria among new MDA achievers. HAQ, health assessment questionnaire; PASI, psoriasis area and severity index; PtGA, patient's global assessment; SJC28, 28-item swollen joint count, TJC28, 28-item tender joint count.

studies have also identified shorter symptom duration, greater general well-being (global VAS), ${ }^{24}$ younger age, higher CRP and lower Bath Ankylosing Spondylitis Functional Index (BASFI) as significant predictors of MDA, which however, were not confirmed in our study. ${ }^{26}$ Moreover, other studies have shown that baseline lower HAQ, higher SJC and no previous use of anti-TNF- $\alpha$ therapy are also prognostic factors of remission at 12 months of treatment. $^{27} 28$

The current results also showed that the most common limiting factors among patients who achieved MDA included pain, PtGA and PASI. Among patients who achieved near-MDA, the most commonly unmet criteria were pain, PtGA and HAQ. These results highlight the difference in perception of disease activity by physicians and patients in the relative importance placed on specific disease aspects.

All disease parameters showed a statistically significant improvement at 6 months of treatment and were sustained over the 12-month period. In a prospective cohort study by Saber et al, statistically significant improvements in clinical outcome measures were also observed for TJC28, SJC28, CRP and HAQ at 12 months in patients treated with anti TNF- $\alpha$ therapy ( $<<0.001$ for all), wherein statistical improvement was achieved within the first 3 months of treatment. ${ }^{27}$

The limitations of the current study are that the peripheral joint activity was measured using the $28 \mathrm{TJC} / \mathrm{SJC}$ although the Outcome Measures in Rheumatology Clinical Trials (OMERACT) recommends the measure of 68 TJC/66 SJC. ${ }^{16}$ However, simplified joint counts have been shown to be sufficiently sensitive to measure clinical response in patients with PsA. ${ }^{29}$ Furthermore, although several approaches were used to assess disease activity, radiographic images are not collected in BioTRAC, therefore not allowing the examination of radiographic progression. There is also potential bias given the observational nature of the study, a bias that is avoided when using data from clinical trials. In addition, a considerable number of patients did not have available MDA information at follow-up due to incomplete data, therefore there is risk for selection bias. In a drop-out analysis no statistical differences were observed between patients with and without MDA information, however, the latter had numerically higher TJC $(8.0 \mathrm{vs}$ 6.4 ) and enthesitis count (5.4 vs 4.5). Furthermore, given that patients treated with either IFX or GLM were included and the profile of patients selected for each treatment may differ, there is risk for confounding by indication. However, the comparison of the two treatments was not within the scope of the current analysis and adjusted estimates were produced for MDA achievement. The strength of the study is that patients were seen in a real-world setting by Canadian rheumatologists during routine clinical practice which enhances the generalisability of the results to the target population.

In conclusion, our results showed overall improvement in clinical parameters and disease activity in patients with PsA patients with IFX or GLM during the 2-year follow-up. By 6 and 12 months of treatment almost $50 \%$ of patients achieved MDA, and among achievers of MDA the most commonly unmet criteria were patient-reported pain, PtGA and PASI. Furthermore, lower baseline HAQ and lower TJC at baseline, were identified as significant prognostic factors of MDA achievement. This study provides evidence supporting the validity of MDA in real world and its usefulness in patient management under routine clinical care.

\section{Author affiliations}

${ }^{1}$ Medicine, Memorial University of Newfoundland, St. Johns, Newfoundland, Canada

${ }^{2}$ Rheumatology, Hôpital Maisonneuve-Rosemont, Montreal, Quebec, Canada

${ }^{3}$ Infectious and immune diseases, Centre Hospitalier de I'Université Laval, Quebec City, Quebec, Canada

${ }^{4}$ Rheumatology, Ontario Medical Association, Toronto, Ontario, Canada

${ }^{5}$ Rheumatology, Centre Hospitalier de l' Université de Montréal, Montreal, Quebec,

Canada

${ }^{6}$ Rheumatology, Credit Valley Rheumatology, Mississauga, Ontario, Canada

${ }^{7}$ Rheumatology, Saint Paul's Hospital, Vancouver, British Columbia, Canada

${ }^{8}$ Rheumatology, University of Ottawa, Ottawa, Ontario, Canada

${ }^{9}$ JSS Medical Research Inc., St-Laurent, Quebec, Canada

${ }^{10}$ Janssen Inc., Toronto, Ontario, Canada 
Contributors PR, MZ, LB, PB, BH and JK substantially contributed to the acquisition of the data for the work and revised the manuscript for important intellectual property. ER, AJL, FN, BO and CT substantially contributed to the conception or design of the work and the interpretation of the data for the work, and revised the manuscript critically for important intellectual content. EP substantially contributed to the analysis and interpretation of data for the work and drafted the manuscript. All authors approved the version to be published and agreed to be accountable for all aspects of the work in ensuring that questions related to the accuracy or integrity of any part of the work were appropriately investigated and resolved.

Funding The sponsor company, Janssen, participated in the study design and interpretation of the data and funded all aspects of the study but did not have an impact on data collection or the decision to submit the article for publication. The writing was conducted by a third party and the sponsor critically reviewed the manuscript.

Competing interests PR, MZ, AC, SK, LB, PB, BH, JK reports personal fees from Janssen during the conduct of the study. PR reports personal fees from Abbott, AbbVie, Amgen, BMS, Celgene, Novartis, Pfizer, Roche outside the submitted work. LB reports personal fees from Amgen, BMS, Roche, UCB, AbbVie, Pfizer, Merck, Sanofi, Celgene, Lilly, Novartis outside the submitted work. PB reports personal fees from AbbVie, Amgen, BMS, Pfizer, Roche outside the submitted work. BH reports personal fees from AbbVie, Amgen, BMS, Celgene, Pfizer, Roche, UCB outside the submitted work. JK reports personal fees from Abbott, AstraZeneca, BMS, MerckSchering, Lilly, Pfizer, Wyeth, Roche, Takeda, UCB outside the submitted work. ER and EP report personal fees from Janssen as employees of JSS Medical Research, the $\mathrm{CRO}$ hired, during the conduct of the study. AJL, FN, BO and CT report personal fees as employees of Janssen during the conduct of the study.

Patient consent Obtained.

Ethics approval Ethics approval for participation in the BioTRAC programme was obtained from the respective research ethics boards of participating institutional sites and a central institutional review board (IRB Services, Ontario Canada) for private practice sites.

Provenance and peer review Not commissioned; externally peer reviewed.

Data sharing statement № additional data are available.

Open Access This is an Open Access article distributed in accordance with the Creative Commons Attribution Non Commercial (CC BY-NC 4.0) license, which permits others to distribute, remix, adapt, build upon this work non-commercially, and license their derivative works on different terms, provided the original work is properly cited and the use is non-commercial. See: http://creativecommons.org/ licenses/by-nc/4.0/

(C) Article author(s) (or their employer(s) unless otherwise stated in the text of the article) 2017. All rights reserved. No commercial use is permitted unless otherwise expressly granted.

\section{REFERENCES}

1. Sonoda $\mathrm{KH}$, Inaba S, Ariyama A, et al. Therapeutic neutrophil apheresis in patients with ocular Behçet disease. Arch Ophthalmol 2005;123:267-9.

2. Khraishi M, Chouela $\mathrm{E}$, Bejar $\mathrm{M}$, et al. High prevalence of psoriatic arthritis in a cohort of patients with psoriasis seen in a dermatology practice. J Cutan Med Surg 2012;16:122-7.

3. Kane D, Stafford L, Bresnihan B, et al. A prospective, clinical and radiological study of early psoriatic arthritis: an early synovitis clinic experience. Rheumatology 2003;42:1460-8.

4. McHugh NJ, Balachrishnan C, Jones SM. Progression of peripheral joint disease in psoriatic arthritis: a 5-yr prospective study. Rheumatology 2003;42:778-83.

5. Gladman DD, Stafford-Brady F, Chang $\mathrm{CH}$, et al. Longitudinal study of clinical and radiological progression in psoriatic arthritis. $J$ Rheumatol 1990;17:809-12.

6. Wong K, Gladman DD, Husted J, et al. Mortality studies in psoriatic arthritis: results from a single outpatient clinic. I. Causes and risk of death. Arthritis Rheum 1997;40:1868-72.

7. Husted JA, Gladman DD, Farewell VT, et al. Health-related quality of life of patients with psoriatic arthritis: a comparison with patients with rheumatoid arthritis. Arthritis Rheum 2001;45:151-8.
8. Husted JA, Tom BD, Farewell VT, et al. A longitudinal study of the effect of disease activity and clinical damage on physical function over the course of psoriatic arthritis: does the effect change over time? Arthritis Rheum 2007;56:840-9.

9. Gladman DD, Antoni C, Mease P, et al. Psoriatic arthritis: epidemiology, clinical features, course, and outcome. Ann Rheum Dis 2005;64(Suppl 2):ii14-ii17.

10. Yu AP, Tang J, Xie J, et al. Economic burden of psoriasis compared to the general population and stratified by disease severity. Curr Med Res Opin 2009;25:2429-38.

11. Schoels M, Knevel R, Aletaha D, et al. Evidence for treating rheumatoid arthritis to target: results of a systematic literature search. Ann Rheum Dis 2010;69:638-43.

12. National institute for health and clinical excellence. The management of rheumatoid arthritis in adults. 2009 http://www.nice.org.uk/ guidance/cg79 (accessed 28 Mar 2016).

13. Gladman DD, Mease PJ, Ritchlin CT, et al. Adalimumab for longterm treatment of psoriatic arthritis: forty-eight week data from the adalimumab effectiveness in psoriatic arthritis trial. Arthritis Rheum 2007;56:476-88.

14. Mease PJ, Kivitz AJ, Burch FX, et al. Etanercept treatment of psoriatic arthritis: safety, efficacy, and effect on disease progression. Arthritis Rheum 2004;50:2264-72.

15. van der Heijde D, Kavanaugh A, Gladman DD, et al. Infliximab inhibits progression of radiographic damage in patients with active psoriatic arthritis through one year of treatment: results from the induction and maintenance psoriatic arthritis clinical trial 2. Arthritis Rheum 2007;56:2698-707.

16. Coates LC, Fransen J, Helliwell PS. Defining minimal disease activity in psoriatic arthritis: a proposed objective target for treatment. Ann Rheum Dis 2010;69:48-53.

17. Coates LC, Cook R, Lee K-A, et al. Frequency, predictors, and prognosis of sustained minimal disease activity in an observational psoriatic arthritis cohort. Arthritis Care Res 2010;62:970-6.

18. Coates LC, Helliwell PS. Validation of minimal disease activity criteria for psoriatic arthritis using interventional trial data. Arthritis Care Res 2010;62:965-9.

19. Coates LC, Moverley AR, McParland L, et al. Effect of tight control of inflammation in early psoriatic arthritis (TICOPA): a UK multicentre, open-label, randomised controlled trial. Lancet 2015;386:2489-98.

20. Thorne C, Bensen WG, Choquette D, et al. Effectiveness and safety of infliximab in rheumatoid arthritis: analysis from a Canadian multicenter prospective observational registry. Arthritis Care Res 2014;66:1142-51.

21. Mease PJ, Heckaman M, Kary S, et al. Application and modifications of minimal disease activity measures for patients with psoriatic arthritis treated with adalimumab: subanalyses of ADEPT. $J$ Rheumatol 2013;40:647-52.

22. Haddad A, Thavaneswaran A, Ruiz-Arruza I, et al. Minimal disease activity and anti-tumor necrosis factor therapy in psoriatic arthritis. Arthritis Care Res 2015;67:842-7.

23. Lubrano E, Perrotta FM, Parsons WJ, et al. Patient's global assessment as an outcome measure for psoriatic arthritis in clinical practice: a surrogate for measuring low disease activity? J Rheumatol 2015;42:2332-8.

24. Theander E, Husmark T, Alenius GM, et al. Early psoriatic arthritis: short symptom duration, male gender and preserved physical functioning at presentation predict favourable outcome at 5-year follow-up. Results from the Swedish Early Psoriatic Arthritis Register (SwePsA). Ann Rheum Dis 2014;73:407-13.

25. Kavanaugh $A$, van der Heijde D, Beutler A, et al. Patients with psoriatic arthritis who achieve minimal disease activity in response to golimumab therapy demonstrate less radiographic progression: Results through 5 years of the randomized, placebo-controlled, GOREVEAL study. Arthritis Care Res 2015.

26. Iervolino S, Di Minno MN, Peluso R, et al. Predictors of early minimal disease activity in patients with psoriatic arthritis treated with tumor necrosis factor- $\alpha$ blockers. J Rheumatol 2012;39:568-73.

27. Saber TP, Ng CT, Renard G, et al. Remission in psoriatic arthritis: is it possible and how can it be predicted? Arthritis Res Ther 2010;12:R94.

28. Eder L, Chandran V, Schentag CT, et al. Time and predictors of response to tumour necrosis factor-alpha blockers in psoriatic arthritis: an analysis of a longitudinal observational cohort. Rheumatology 2010;49:1361-6.

29. Englbrecht M, Wang $Y$, Ronneberger $M$, et al. Measuring joint involvement in polyarticular psoriatic arthritis: an introduction of alternatives. Arthritis Care Res 2010;62:977-83. 